\title{
A Retrospective Analysis on Types of Flap Design Used in Maxillary Carcinoma
}

\section{IJCRR}

Section: Healthcare

Sci. Journal Impact

Factor: 6.1 (2018)

ICV: 90.90 (2018)

(c) (i) (5)

Copyright@IJCRR

\section{Harini G1 ${ }^{1}$ Kathiravan Selvarasu2 ${ }^{2}$, Bala Krishna R N²}

'Saveetha Dental College and Hospitals, Saveetha Institute of Technical and Medical Sciences, Saveetha University, Chennai - 60o o77, India; ${ }^{2}$ Senior Lecturer, Department of Oral and Maxillofacial Surgery, Saveetha Dental College and Hospitals, Saveetha Institute of Technical and Medical Sciences, Saveetha University, Chennai -60o o77, India.

\section{ABSTRACT}

Introduction: The removal of various maxillary tumors and further reconstruction is considered as a difficult phase.

Objective: The aim of the study is to investigate the flap design used in maxillary carcinoma at Saveetha Dental College.

Methods: This study was conducted for the patients who visited the Department of oncology between 1st June 2019-1st April 2020. Data was extracted by reviewing the information of the patient.

Results: Out of 57 patients 17 patients (30\%) were diagnosed with maxillary carcinoma. There was male predilection in this sample with $58.82 \%$ males and $41.18 \%$ females. Weber-Fergusson approach along with the modifications was used in $76.47 \%$, midfacial degloving in $17.65 \%$ and palatal swing approach in $5.68 \%$ of the patients with maxillary carcinoma.

Conclusion: We conclude that maxillary carcinoma resection was done predominantly among males and the most common age group which underwent surgical treatment for the same were in the age group of 41 to 50 years. Among various flaps used to resect the tumor, Weber-Fergusson (76.47\%) was used in the majority of cases. Association between gender and age and type of flap used of maxillary carcinoma resection was tested using Chi-square analysis and it was found to be not significant.

Key Words: Maxillary, Carcinoma, Incision, Flap, Weber Fergusson

\section{INTRODUCTION}

Maxillary carcinoma, where oral squamous cell carcinoma represents $90-95 \%$ of all malignant neoplasms in the oral cavity. ${ }^{1}$ The classical cause of this disease has a high correlation with alcohol and tobacco consumptions. ${ }^{2}$ This maxillary carcinoma accounts for $56 \%$ of the oral cancer. Malignancies of the nasal cavity and paranasal sinuses are rare, accounting for only $3 \%$ of head and neck carcinoma and about $0.5 \%$ of all malignant disease. The annual incidence rate is $0.5-1.0$ per 100,000 population. These tumors are two times more frequently observed in men than in women, mainly between 50 and 70 years old. Of these malignancies, $80 \%$ originate from the maxillary sinus and histologically, $60-90 \%$ of these cases have been shown to be squamous cell carcinoma. The surgical treatment for tumor invading the maxilla with adequate surgical margins is challenging because of the anatomic complexity of the maxillofacial region. ${ }^{3}$ The removal of various maxillary tumors and further reconstruction is considered as a difficult phase. These are treated by the com- bined approach of surgery, chemotherapy and radiotherapy. ${ }^{4}$ The surgical resection therefore remains as the initial treatment which is used as the treatment of choice for all tumors of nasal, paranasal, and sinuses. Henceforth the incisions and the approach should be suitably done depending on the stage of the tumor. ${ }^{5}$ However, advanced techniques and experience in surgical tumor resection and reconstructive techniques has afforded many patients the opportunity for curative surgery than in previous decades. ${ }^{6}$

Out of many approaches to the maxillary region, the commonly used approaches are the Weber-Fergusson's incision and the Midfacial degloving incision. A controversy exists regarding who described these incisions first. Few authors consider Weber-Fergusson incision was first described by Gensoul 1893 later the technique was popularized in 1960 by Weber and Fergusson. The others argue that it was first described by Weber in the German literature and was later modified by Fergusson in the English literature. And some people believe that Sir William Fergusson was the person

\section{Corresponding Author:}

Dr. Kathiravan Selvarasu, Senior Lecturer, Department of Oral and Maxillofacial Surgery, Saveetha Dental College and Hospitals, Saveetha Institute of Technical and Medical Sciences, Saveetha University, Chennai - 600 077, Email: kathiravan.sdc@saveeetha.com

ISSN: 2231-2196 (Print)

Received: 16.09 .2020
ISSN: 0975-5241 (Online)

Revised: 17.10 .2020
Accepted: 14.11 .2020
Published: 26.12 .2020 
who described the technique and Weber has described the mandibular procedure. However, these standard techniques underwent various modifications depending on the extent of the tumor. ${ }^{7}$

This article aims to study the flap design used in surgical management of maxillary carcinoma in a University setting.

\section{MATERIALS AND METHODS}

Subjects were the patients who visited Saveetha Dental College and Hospitals, Department of Oncology and these patients are all grouped according to the gender and design of flaps used in the treatment for tumor resections

This study was approved by the ethical committee for research at Saveetha Dental College: SDC/SIHEC/2020/DIASDATA/0619-0320.

Data according to the patient was collected by reviewing 86,000 patients, where 57 tumor patients were screened and 17 maxillary tumor patients were included in the study. The patient intra oral photos, history presenting illness, and systematic diseases were accessed.

\section{Inclusion Criteria}

Patient with maxillary carcinoma

- Squamous cell carcinoma

- Venomous carcinoma

- Lymphoma

- Mucosal melanoma

- Kaposi sarcoma

- Odontogenic sarcoma

\section{Exclusion Criteria}

- Mandibular carcinoma

- People under 18 years of age

- Physically challenged

- People who underwent radiotherapy and chemotherapy treatment

\section{Statistical Analysis}

The data was tabulated and analyzed using IBM SPSS version 2.0. Non-parametric data were analyzed using descriptive statistics measuring percentage and frequency. The association between Type of flap used in Maxillary Carcinoma, age, and gender was done with Pearson's Chi-square test.

\section{RESULT}

The chats and records from the oncology department case records identified $17(30 \%)$ maxillary carcinoma patients from 57 over all cases of carcinoma in oral cavity between 1st June 2019 - 1st April 2020. Gender distribution was as- sessed and a male predominance noted with an incidence of $58.82 \%$ and females accounting for $41.18 \%$ (Figure 1). Patients involved belonged predominantly to elderly age group ranging from 40 to 70 years. The mean age of the patient was 46 years (Figure 2). The flap designs used to excise carcinoma was predominantly Weber Fergusson in $76.47 \%$ of cases, followed by midfacial degloving in $17.65 \%$ of cases and palatal swing approach in $5.88 \%$ of cases (Figure 3 ). The association between flap design and gender of the study population was found using Chi-square test and it was statistically not significant [Chi-square value-0.909; $\mathrm{p}$-value- 0.635 $(p>0.05)$ ] (Figure 4). Association between age and design of flap was found using Chi-square test and it was statistically not significant [Chi-square value-1.308; $\mathrm{p}$-value- 0.860 $(\mathrm{p}>0.05)]$ (Figure-5).

\section{DISCUSSION}

According to this study, a male predominance (58.82\%) was noted in the sample, which could be explained by extensive proof in literature regarding high incidence of carcinoma cases in males. The mean age of patients who got operated for maxillary carcinoma was 41-50 years. Weber fergusson flap design was used in the majority of cases to approach and excise the carcinoma ( $76.47 \%$ cases) and other incisions used were midfacial degloving ( $17.65 \%$ cases) and palatal swing approach $(5.88 \%$ cases). This correlates with the study done by Rajasekar et al. and Kranti bhavan $86 \%$ of the patients treated with the Weber-Fergusson method, midline degloving accounts to $14 \%$ of the incision. It was evaluated for the overall advantage and disadvantage of the approach, with regards to physiological functions, aesthetic outcome and complications. ${ }^{8}$ The study conducted by Cario university showed that the majority of the patients underwent the mid facial degloving approach showed no significant complications which is not in accordance to our results. ${ }^{9}$

The genesis and the progress of oral carcinoma is a complex process involving enormous pathological changes in the form, structure and function of the region involved. Maxillary carcinomas can lead to both aesthetic disfigurement and functional disability; hence extreme care should be exercised when a surgical planning is performed. The surgical approach for maxillary tumors depends on the spread and simultaneous involvement of important structures by the tumor. Primary aim of the approach should provide adequate exposure without damaging the functional tissue and to provide cosmetic integrity.

Few commonly used surgical approaches for maxillary exploration and carcinoma management are transoral-vestibular approach, Trans-palatal approach, Weber-Fergusson approach were made to perform maxillectomy procedures. ${ }^{10}$ The Weber Ferguson approach was introduced in the 1960's 
and is still being widely used due to its advantages like excellent exposure and minimal scarring as they follow natural skin crease healing. This approach is generally used with the various modifications.

Weber Ferguson incision

Weber Ferguson incision with Lynch extension

Weber Ferguson incision with lateral subciliary extension

Weber Ferguson incision with subciliary and supraciliary extension.

The modifications are chosen based on the carcinoma size, site, spread, adjacent structures involved, and extent of exposure needed. However handling the soft-tissues during Weber Fergusson incision is challenging and complicated during resection.

Transpalatal approach for nasopharyngeal tumor offered good exposure to mid third of face with excellent cosmetic results. It provides a wide and comfortable exposure to the midfacial region. This approach generally has a high tendency of bleeding causing damage to vital structures and formation of hematoma which can lead to secondary infections. Among various approaches used in the maxillary region and paranasal region, the most commonly used approach was the Weber-Fergusson flap design and the midline facial degloving approach. ${ }^{11}$

Considerable studies have been conducted in the field of Surgery with relevance to the current population under study. ${ }^{12-26}$ This study is based on a limited sample size from SouthIndian population, performed in a shorter span of one year. To improve the scope of the research, in future studies can be planned including a larger population and longer follow up.

\section{CONCLUSION}

Within the limitations of this study, we conclude that maxillary carcinoma resection was done predominantly among males and most common age groups which underwent surgical treatment were in the age group of 41 to 50 years. Among various flaps used to resect the tumor, Weber-Fergusson $76.47 \%$ was used in the majority of cases, followed by midline degloving and transpalatal approach. Association between gender and age and type of flap used of maxillary carcinoma resection was tested using Chi-square analysis and it was found to be not significant. Several approaches have been used for the resection of the tumor in maxilla, but each of them has got inherent advantages and disadvantages. Preserving the vital structure and improving the ease of operating technique remains the objective of successful treatment which is achievable with Weber Ferguson approach and its modification.

\section{AUTHORS CONTRIBUTION}

First author (Harini G) performed analysis, interpretation, and wrote the manuscript. Second author (Dr. Kathiravan Selvarasu) contributed to conception, data designs, analysis, interpretation, and critically revised the manuscript. Third author (Dr. Bala Krishnan R N) participated in the study and revised the manuscript. All the three authors have discussed the results and contributed to the final manuscript.

Conflict of Interest: There are no conflicts of interest

\section{ACKNOWLEDGEMENT}

This study was supported by Saveetha Institute of Technical and Medical Sciences, Chennai.

\section{REFERENCES}

1. Moore SR, Johnson NW, Pierce AM, Wilson DF. The epidemiology of mouth cancer: a review of global incidence. Oral Dis 2008;6:65-74.

2. Bradford J. SP212- Oral cavity squamous cell carcinoma posttransplantation. Otolaryngol Head Neck Surg 2009;141:P159_ 60.

3. Franchi A, Bishop JA. Nonsquamous Lesions of the Nasal Cavity, Paranasal Sinuses, and Nasopharynx. Gnepp's Diagnostic Surgical Pathology of the Head and Neck 2021:126-87.

4. Patel R, Novak C, Neligan P. Reconstruction of the Oral Cavity and Oropharynx. Principles and Practice of Head and Neck Surg and Oncol Second Edition 2009:541-55.

5. Thankappan K, Vidhyadharan S, Iyer S. Principles of Surgery in Oral Cavity Cancers. Basic Concepts Head Neck Surg Oncol 2015:158-158.

6. Day TA, Beas RA, Schlosser RJ, Woodworth BA, Barredo J, Sharma AK, et al. Management of paranasal sinus malignancy. Curr Treat Opt Oncol 2005;6:3-18.

7. Shah JP, Johnson NW, Batsakis JG, Batsakis JG. Oral Cancer. Thieme 2003:496.

8. Rajasekhar G, Vura NG, Sudhir R, Dhanala S, Alwala AM. Versatility of Dieffenbach's Modification of Weber Fergusson's Approach for Treatment of Maxillary Pathologies. J Maxillofac and Oral Surg 2012;11:416-9.

9. Ferreira LM de BM, de Brito Macedo Ferreira LM, do Nascimento Rios AS, Gomes ÉF, Azevedo JF, de Paula Araújo R, et al. Midfacial degloving - acess to nasal cavity and paranasal sinuses lesions. Brazilian J Otorhinolaryngol 2006;72:158-62.

10. Chen W-L, Chen Z-W, Yang Z-H, Huang Z-Q, Li J-S, Zhang B, et al. Pedicled Mandibular Osteomuscular Flap for Zygomatic Reconstruction Through a Modified Weber-Ferguson Incision. J Craniofac Surg 2008;19:235-40.

11. Whiteman DC, Wilson LF. The fractions of cancer attributable to modifiable factors: A global review. Cancer Epidemiol 2016;44:203-21.

12. Jesudasan JS, Abdul Wahab PU, Muthu Sekhar MR. Effectiveness of $0.2 \%$ chlorhexidine gel and a eugenol-based paste on postoperative alveolar osteitis in patients having third molars extracted: a randomised controlled clinical trial. Br J Oral Maxillofac Surg 2015;53:826-30.

13. Kumar S, Rahman R. Knowledge, Awareness, And Practices Re- 
garding Biomedical Waste Management Among Undergraduate Dental Students. Asian J Pharma Clin Res 2017;10:341.

14. Jain SV, Vijayakumar Jain S, Muthusekhar MR, Baig MF, Senthilnathan P, Loganathan S, et al. Evaluation of Three-Dimensional Changes in Pharyngeal Airway Following Isolated Lefort One Osteotomy for the Correction of Vertical Maxillary Excess: A Prospective Study. J Maxillofac Oral Surg 2019;18:139-46.

15. Patturaja K, Pradeep D. Awareness of Basic Dental Procedure among General Population. Res J Pharm Tech 2016;9:1349.

16. Abhinav RP, Sweta VR, Ramesh A. Role of virtual reality in pain perception of patients following the administration of local anesthesia. Annals of Maxillofac Surg 2019;9:110.

17. Kumar S. Knowledge, Attitude And Awareness Of Dental Undergraduate Students Regarding Hiv/Aids Patients. Asian J Pharma Clin Res 2017;10:175.

18. Kumar S. The Emerging Role Of Botulinum Toxin In The Treatment Of Orofacial Disorders: Literature Update. Asian J Pharma Clin Res 2017;10:21.

19. Kumar S, Sneha S. Knowledge And Awareness Regarding Antibiotic Prophylaxis For Infective Endocarditis Among Undergraduate Dental Students. Asian J Pharma Clin Res 2016:154.

20. Abhinav RP, Selvarasu K, Maheswari GU, Taltia AA. The Patterns and Etiology of Maxillofacial Trauma in South India. Ann Maxillofac Surg 2019;9(1):114-7.

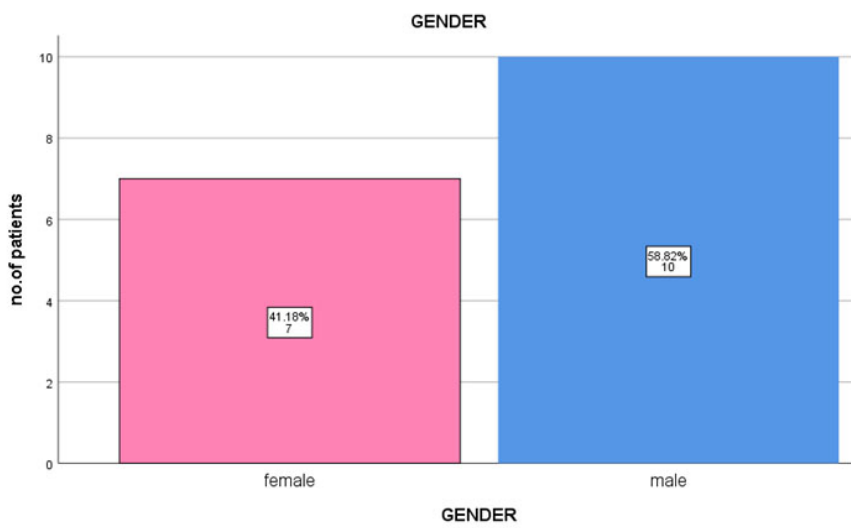

Figure 1: Bar Graph showing the gender distribution. X-axis corresponds to the gender and $\mathrm{Y}$-axis corresponds to the number of patients with maxillary carcinoma. Pink denotes females and blue denotes males. A male predominance was noted. Males - 58.82\%, Females - 41.18\%
21. Rao TD, Santhosh Kumar MP. Analgesic Efficacy of Paracetamol Vs Ketorolac after Dental Extractions. Res J Pharm Tech 2018;11:3375.

22. Patil SB, Durairaj D, Suresh Kumar G, Karthikeyan D, Pradeep D. Comparison of Extended Nasolabial Flap Versus Buccal Fat Pad Graft in the Surgical Management of Oral Submucous Fibrosis: A Prospective Pilot Study. J Maxillofac Oral Surg 2017;16:312-21.

23. Kumar S. Relationship Between Dental Anxiety And Pain Experience During Dental Extractions. Asian J Pharma Clin Res 2017; 10:458.

24. Packiri S. Management of Paediatric Oral Ranula: A Systematic Review. J Clin Diag Res 2017;21:87-92.

25. Marimuthu M, Andiappan M, Wahab A, Muthusekhar MR, Balakrishnan A, Shanmugam S. Canonical Wnt pathway gene expression and their clinical correlation in oral squamous cell carcinoma. Indian J Dent Res 2018;29(3):291-7.

26. Christabel A, Anantanarayanan P, Subash P, Soh CL, Ramanathan M, Muthusekhar MR, et al. Comparison of pterygomaxillary dysjunction with tuberosity separation in isolated Le Fort I osteotomies: a prospective, multi-centre, triple-blind, randomized controlled trial. Int J Oral Maxillofac Surg 2016;45:180-5.

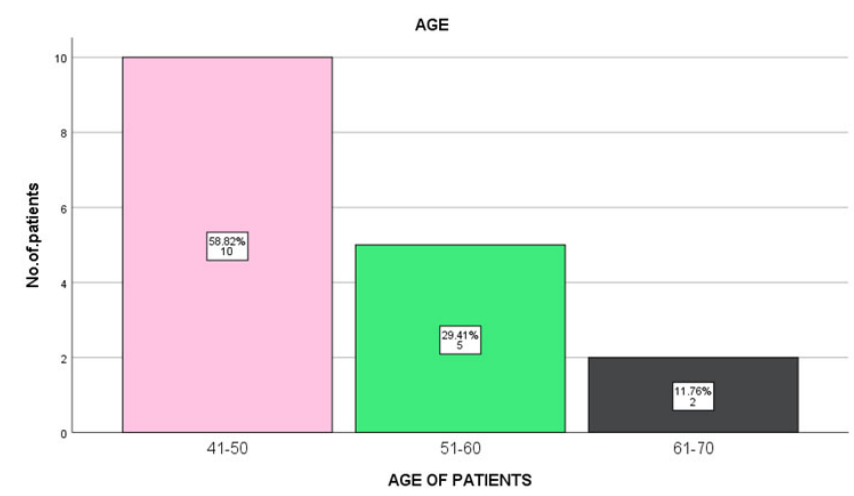

Figure 2: Bar Graph showing the age distribution. X-axis corresponds to the age and $Y$-axis corresponds to the number of patients with maxillary carcinoma. The color pale pink denotes 41-50 years, pastel green denotes 51-60 years and black denotes $61-70$ years of age. The highest number of patients was seen between the ages of $41-50$ years of age $(46.15 \%)$. 


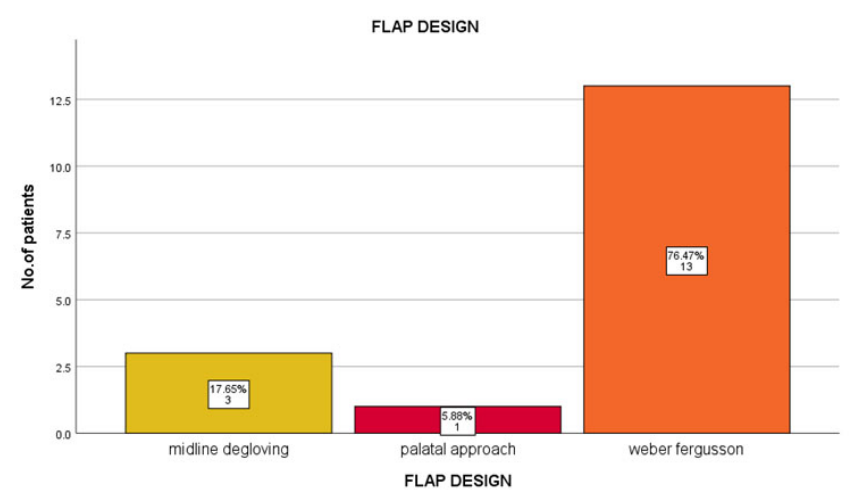

Figure 3: Bar Graph showing the flap design used in maxillary carcinoma. X-axis corresponds to the design of flap and $\mathrm{Y}$ axis corresponds to the number of patients. The mustard color denotes Midline degloving, magenta denotes palatal approach and saffron denotes Weber-Fergusson. The most commonly used flap was Weber-Fergusson $76.47 \%$.

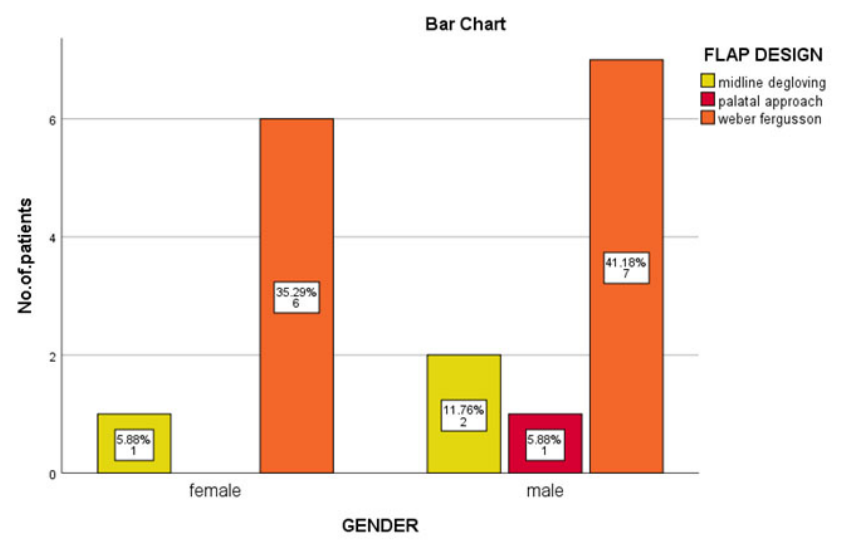

Figure 4: Bar graph showing the association between flap design and gender of the study population. X-axis corresponds to the gender affected and $Y$-axis corresponds to the number of patients. All three flap design was used in males (WeberFergusson (saffron) - 41.18\%, Midlfacial-degloving (mustard) - $11.76 \%$, palatal approach (magenta) - 5.88\%) and females with (Weber-Fergusson - 35.29\%, midfacial degloving-5.88\%). Chi-square test was done to find the association between gender and flap design and was found to be statistically not significant [Chi-square value-0.909; $p$-value- 0.635 ( $p>0.05$ ).

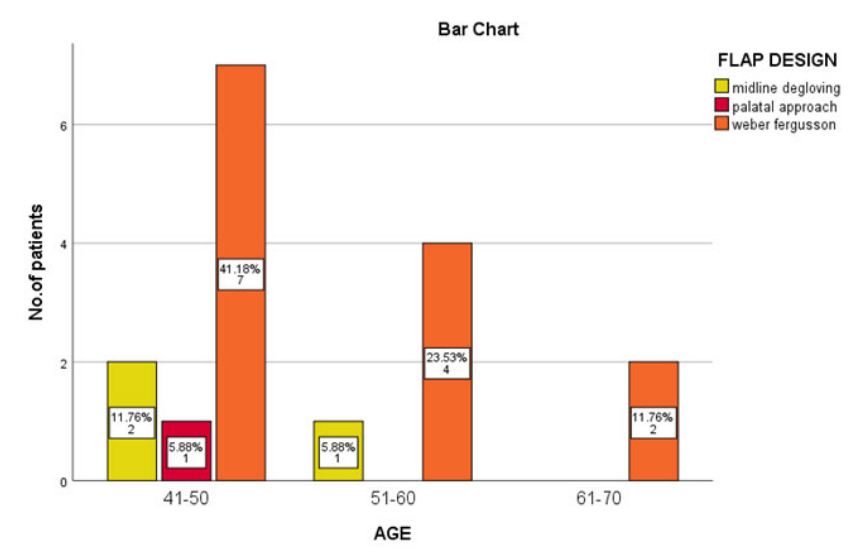

Figure 5: Graph showing the association between age and design of flap used. $\mathrm{X}$-axis corresponds to the age and $\mathrm{Y}$-axis corresponds to the design of flap used. The color mustard denotes midline degloving, magenta denotes palatal approach, and dark orange denotes Weber-Fergusson flap. 41-50 years had a higher prevalence of lesion and Weber-Fergusson $(41.18 \%)$ and midline degloving $(11.76 \%)$. Chi-square test was done to find the association between flap design and age group and was found to be statistically not significant [Chisquare value-1.308; $p$-value- $0.860(p>0.05)]$. 